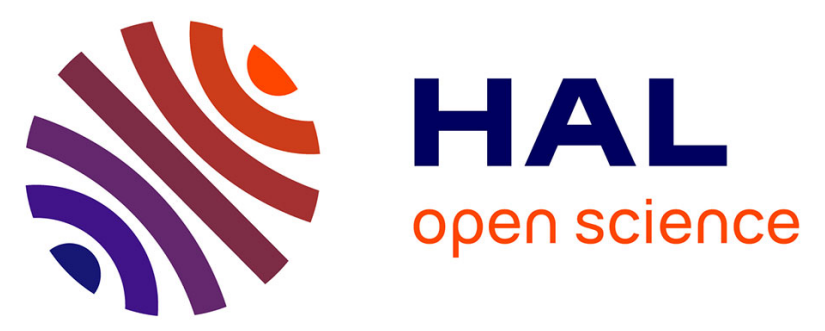

\title{
Angiography and Percutaneous Coronary Intervention for Chronic Total Coronary Occlusion in Daily Practice (from a Large French Registry [CARDIO-ARSIF])
}

Madjid Boukantar, Aurélie Loyeau, Romain Gallet, Sophie Bataille, Hakim Benamer, Christophe Caussin, Philippe Garot, Bernard Livarek, Olivier Varenne, Christian Spaulding, et al.

\section{To cite this version:}

Madjid Boukantar, Aurélie Loyeau, Romain Gallet, Sophie Bataille, Hakim Benamer, et al.. Angiography and Percutaneous Coronary Intervention for Chronic Total Coronary Occlusion in Daily Practice (from a Large French Registry [CARDIO-ARSIF]). American Journal of Cardiology, 2019, 124, pp.688 - 695. 10.1016/j.amjcard.2019.05.062 . hal-03488127

\section{HAL Id: hal-03488127 \\ https://hal.science/hal-03488127}

Submitted on 20 Dec 2021

HAL is a multi-disciplinary open access archive for the deposit and dissemination of scientific research documents, whether they are published or not. The documents may come from teaching and research institutions in France or abroad, or from public or private research centers.
L'archive ouverte pluridisciplinaire HAL, est destinée au dépôt et à la diffusion de documents scientifiques de niveau recherche, publiés ou non, émanant des établissements d'enseignement et de recherche français ou étrangers, des laboratoires publics ou privés.

\section{(ㄷ)(1) $\$$}

Distributed under a Creative Commons Attribution - NonCommerciall 4.0 International 
Angiography and Percutaneous Coronary Intervention for Chronic Total Coronary Occlusion in Daily Practice (from a Large French Registry [CARDIO-ARSIF])

Authors Madjid Boukantar MD a, Aurélie Loyeau $\mathrm{PhD}^{\mathrm{b}}$, Romain Gallet MD ${ }^{\mathrm{a}}$, Sophie Bataille MD ${ }^{\mathrm{b}}$, Hakim Benamer MD ${ }^{\mathrm{c}}$, Christophe Caussin MD ${ }^{\mathrm{d}}$, Philippe Garot MD ${ }^{\mathrm{c}}$, Bernard Livarek MD ${ }^{\mathrm{e}}$, Olivier Varenne MD, $\mathrm{PhD}^{\mathrm{f}}$, Christian Spaulding MD, $\mathrm{PhD}{ }^{\mathrm{g}}$, Gaëtan Karrillon $\mathrm{MD}^{\mathrm{e}}$, Emmanuel Teiger MD, $\mathrm{PhD}^{\mathrm{a}}$

${ }^{a}$ Interventional Cardiology, University Hospital Henri Mondor, Assistance PubliqueHôpitaux de Paris, France

${ }^{\mathrm{b}}$ Agence Régionale de Santé d'Ile-de-France (ARSIF)

${ }^{\mathrm{c}}$ Hôpital Privé Jacques Cartier, Institut Cardiovasculaire Paris Sud (ICPS), Massy, France

${ }^{\mathrm{d}}$ Cardiology Department, Institut Mutualiste Montsouris, Paris, France

${ }^{\mathrm{e}}$ Cardiology Department, Versailles Hospital (André Mignot), Le Chesnay, France;

${ }^{\mathrm{f}}$ Cardiology Department, University Hospital Cochin, Assistance Publique-Hôpitaux de Paris, France

g Cardiology Department, European Georges Pompidou Hospital, Assistance PubliqueHôpitaux de Paris, France

${ }^{\mathrm{e}}$ Cardiology Department, Simone Veil Hospital, Eaubonne, France

\section{Corresponding author}

Madjid Boukantar, MD

Interventional Cardiology, University Hospital Henri Mondor, 51 Avenue du Marechal de Lattre de Tassigny ; 94000 Créteil, France

Mail: madjid.boukantar@aphp.fr Phone: +33149812111 Fax: +33181942111

Short title: Current data on CTO from a french registry

Funding: None

Declaration of interest: None 


\begin{abstract}
The aim of this study was to provide contemporary data on chronic total occlusion (CTO) prevalence and management in a large unselected population representing the daily activity of cathlabs, in the greater Paris area, and to compare percutaneous coronary intervention (PCI) features in patients with and without CTO. Procedures were collected from the CARDIOARSIF (Agence Régionale de Santé Ile de France) registry from 2012- 2015. Patients with acute coronary syndrome or previous coronary artery bypass grafting were excluded. CTO features were assessed and PCIs with and without CTO were compared. Among 128739 included patients, $10468(8.1 \%)$ had at least one CTO. Cardiovascular risk-factor burden was higher in the CTO group, which had more patients with multivessel disease (74\% vs $24 \%$ ) and with referral for interventional management (59\% vs 33\%). Of all PCIs during the study period, 5.7\% involved a CTO; this proportion increased significantly over the study period. PCI success rate was $75.9 \%$ in the CTO group. CTO-PCI volume per center did not correlate with CTO-PCI success rate. In conclusion, CTO is common in patients undergoing scheduled coronary angiography. Invasive management is done more often in patients with than without CTO. The success rate of PCI in CTO is not associated with case volume per center.
\end{abstract}

\title{
Key words
}

Chronic coronary total occlusion; Stable angina; Clinical research 


\section{INTRODUCTION}

The true prevalence of coronary chronic total occlusions (CTO) is unclear. Among patients with coronary artery disease (CAD) referred for coronary angiography (CA), $16 \%$ to $52 \%$ have CTO [1-4]. The prevalence of CTO in unselected populations in 3 recent multicenter retrospective studies was $11.5 \%$ to $14.7 \%$ [2,5,6]. Limitations of these studies include the small number of participating centers, short study period, and absence of data collected after 2013. To date, only few studies have assessed the prevalence, and management of CTO in a large unselected population of patients undergoing scheduled heart catheterization in daily practice. Our first objective was to assess the prevalence, clinical characteristics, and management of CTO in stable unselected patients undergoing non-emergent CA. Our secondary objective was to compare percutaneous coronary intervention (PCI) features in patients with and without CTO. To achieve these objectives, we used data from CARDIOARSIF (Agence Régionale de Santé Ile de France), an ongoing prospective regional registry of all patients undergoing CA with or without PCI in the greater Paris area.

\section{METHODS}

The CARDIO-ARSIF registry was initiated in 2001 by the Regional Health Agency of the Greater Paris Area, a governmental agency, to record and monitor all coronary diagnostic and therapeutic procedures performed in 36 catheterization laboratories (7 university, 12 general, 5 nonprofit private, and 12 for-profit private hospitals) of the greater Paris area, which has a population of about 12 million (19\% of the population in France). Each procedure is entered prospectively into a computer database by the physician who performed the procedure. Multiple procedures in the same patient are entered separately. Recorded variables include demographics, pre-procedural clinical status and extensive procedural information. Participation in the registry is mandatory to obtain PCI certification. Internal audits are performed on $10 \%$ of cases twice a year at each center. In addition, an independent external 
random audit of $3 \%$ of cases is performed every 6 months to check data completeness and accuracy. In accordance with French ethical requirements, the CARDIO-ARSIF registry was approved by the French data protection authority (Commission Nationale de l'Informatique et des Libertés, CNIL).

CTO was included among the variables recorded in the CARDIO-ARSIF registry in January 2012. For the purpose of this study, we included all patients who underwent nonemergent CA between January 1, 2012, and December 31, 2015. Among them, we identified those with CTO, defined as $100 \%$ luminal diameter stenosis and absence of antegrade flow, known or assumed to have been present for more than 3 months. To ensure that only chronic lesions were included, we excluded patients receiving emergency care for cardiac arrest, STelevation myocardial infarction (STEMI), or non-STEMI. We also excluded patients with a history of coronary artery bypass grafting (CABG). In the second part of the study, we identified all PCIs performed during the same period, excluding emergent PCIs performed for cardiac arrest, STEMI, or non-STEMI. For each patient in the CTO and non-CTO groups, we recorded demographic data, CA findings and treatment strategies. Features of CTO-PCI and non-CTO-PCI were compared, including demographic and procedural data.

Continuous variables are presented as mean \pm SD or median and quartiles, and categorical variables were reported as percentages. The baseline characteristics were compared between patients with CTO versus without CTO. Treatment strategies were compared between coronary angiograms with CTO versus without CTO. A second set of comparison was performed between PCIs of CTO versus non-CTO PCIs. Differences in baseline characteristics between the groups were tested using the chi-square test or Fisher's exact test for categorical variables and Student's $t$ test or Wilcoxon rank-sum test for continuous variables, as appropriate. Non-parametrics Mann-Whitney U test and KruskalWallis test were used for comparison of continuous non-normally distributed variables in two 
or more independent groups. Tests for trends were made using the Armitage-Cochrane trend test for categorical data. We used logistic regression with test for linear trend to evaluate whether CTO-PCI procedural success was correlated to CTO volume activity per center. $P$ values $<0.05$ were taken to indicate statistically significant differences. Statistical analyses were performed using SAS software version 9.4 (SAS Institute, Cary, NC)

\section{RESULTS}

During the study period, 258526 coronary procedures were performed in the greater Paris area, including 143294 non-emergent CAs in 128739 patients, which form the basis for this study. The flowchart is shown in Figure 1. Of these 128739 patients, $10468(8.1 \%)$ had CTO. CTO was more common in the right coronary artery and branches $(n=6782,47.63 \%)$ than in the left anterior descending artery and branches $(n=3668,25.76 \%)$ and circumflex artery and branches $(\mathrm{n}=3789,26.61 \%)$.

Compared to the non-CTO group, the CTO group had a greater burden of cardiovascular risk factors with higher prevalence of hypertension, dyslipidemia, current smoking, and diabetes. Patients with CTO more often had a history of myocardial infarction, chronic kidney disease, stroke, and/or peripheral vascular disease. Multivessel disease was more common in the CTO group (table 1). In-hospital mortality was not different between CTO patients and non-CTO patients ( $\mathrm{n}=80,0.6 \%$ vs $\mathrm{n}=764,0.8 \%, \mathrm{p}=0.15)$.

PCI to either CTO or non-CTO arteries was undertaken more frequently in the CTO group ( $49 \%$ vs. $33 \%, P<0.0001$ ). Among CAs with CTO, $31 \%$ were extended by ad hoc PCI and $18 \%$ by staged PCI on CTO or non-CTO lesions, compared to $23 \%$ and $10 \%$, respectively, in the non-CTO group. Referral to a heart team was more common in the CTO group than in the non-CTO group $(18 \%$ vs. $7 \%, P<0.0001)$. Referral for CABG was twice as 
common in the CTO group compared to the non-CTO group $(n=1101,10 \%$ vs. $n=6058,5 \%$; $P<0.0001)$ (table 2).

Of the 61469 non-emergent PCIs performed during the study period, 8976 (14.6\%) staged PCIs could not be linked to a previous diagnostic CA and were excluded from our analysis, as were the $2514(4 \%)$ procedures with missing data on lesion severity and the 56 PCIs performed more than 1 year after the diagnostic CA. The flowchart is shown in figure 2 . Of the 49923 remaining PCIs, in 43768 patients, 2829 (5.7\%) were for CTO lesions and 47 094 for non-CTO lesions. In 72 cases, at least 2 CTOs were treated during the same procedure. Table 3 lists the indications for PCI. Multiple accesses were more common in the CTO-PCI group, which had a longer fluoroscopy time and a higher dose-area product. Figure 3 shows that the dose-area product (DAP) was high for most CTO-PCIs. Mean number of stents implanted was higher, total stented length greater, and mean stent diameter lower in the CTO-PCI group (Table 4). In-hospital mortality was not different between CTO-PCIs and non-CTO PCIs $(\mathrm{n}=7,0.25 \%$ vs $\mathrm{n}=194,0.41 \%, \mathrm{p}=0.18)$.

The proportion of CTO-PCIs among all PCIs increased from $2.6 \%$ in 2012 to $7.2 \%$ in $2015(P<0.0001)$. Fluoroscopy time decreased significantly from 2012 to 2014 and remained stable thereafter, whereas the dose-area product continued to decrease $(P<0.0001)$ (Table 5). The procedural success rate was lower for CTO-PCI than for non-CTO-PCI (Table 4). Procedural CTO-PCI success rates improved non-significantly during the study period from 74 to $76 \%$ ( $p=0.19$ ). In the center-by-center analysis, CTO-PCI volume did not correlate with procedural success overall (Figure 4). Even after excluding very low volume centers ( $<25$ CTO procedures/year), CTO-PCI success rates showed no correlation with CTO-PCI volume $(P=0.17)$ (Figure 5).

\section{DISCUSSION}


This large multicenter registry study provides data on CTO in unselected patients undergoing scheduled diagnostic $\mathrm{CA}$ in daily clinical practice in a large urban area. The prevalence of CTO was $8.1 \%$. Both ad hoc and staged PCIs were more common in the presence of a CTO. Of all PCIs performed in these patients managed in the non-emergency setting, 5.7\% were done to treat CTO. CTO-PCI had a lower procedural success rate compared to non-CTO-PCI, as well as greater radiation exposure, a larger number of stents used, a greater stented length, and a lower mean stent diameter. The CTO-PCI procedural success rate was not associated with case volume and showed no significant variation across study centers.

Reported prevalence of CTO varies across populations [1-3,5,7]. Of 6581 patients with at least one $>70 \%$ stenosis, $52 \%$ had CTO [1]. In a population-based sample entered into the Swedish SCAAR registry in $2005-2012$, the prevalence of CTO was $11.5 \%$ overall and $16 \%$ among patients with coronary artery stenosis $>50 \%$ [5]. Coronary emergencies were excluded from these analyses, as they were from ours. In the Italian Registry of Chronic Total Occlusions (IRCO), CTO was noted in $13.3 \%$ of 13423 patients screened in 2007[6]. The lower prevalence of $8.1 \%$ in our study compared to earlier reports may be ascribable to several factors. Of the cases in our registry, $27 \%$ were emergency procedures and were therefore excluded. In the SCAAR registry, $41.8 \%$ of patients with unstable CAD had CTO [5]. Among patients with STEMI, $10 \%$ to $15 \%$ had CTO, regardless of the culprit artery $[8,9]$. In the IRCO, however, only $16.7 \%$ of patients with CTO presented with STEMI or nonSTEMI [6]. In our study, including patients with non-STEMI in the analysis would not substantially change the prevalence of CTO. Recent data suggest that the prevalence of CTO may be declining in western countries, although variations in local practices and populations may act as a confounding factor. A decline in CTO may reflect improved cardiovascular risk management and/or the increasing rate of primary PCI in patients with STEMI and non- 
STEMI. The latter hypothesis is supported by data from the French Registry of Acute STElevation or Non-ST-elevation Myocardial Infarction (Fast-MI). In France, the rate of primary PCI increased from $12 \%$ to $75 \%$ in STEMI and the rate of PCI in non-STEMI patients from $9 \%$ to $60 \%$ between 1995 and 2015 [10].

Treatment strategies differed depending on the presence or not of CTO. Coronary revascularization was performed more often in the CTO group, due to the high proportion of CA without severe coronary stenosis in the non-CTO group. However, the CTO group had a high rate of revascularization by either PCI (49\%) or CABG (10\%). Heart team referral, which usually leads to CABG or PCI, was $18 \%$. Pharmacological therapy alone was used in only $21 \%$ of CTO patients. These results are in contradiction with previous studies. Of our CTO cases, $49 \%$ were managed with staged or ad hoc PCI, compared to $11 \%$ of 1612 cases of CTO in an earlier study [1]. Similarly, in the Canadian CTO registry, only $30 \%$ of patients with CTO underwent PCI, and 40\% received pharmacological therapy only[2]. Another recent US study showed that $50 \%$ of patients with CTO and no prior CABG underwent PCI [3]. Similarly, in the IRCO, $43.7 \%$ of CTOs were managed by PCI[6]. These results confirm that the presence of a CTO is no longer an obstacle to treat coronary stenosis by PCI.

The $75.7 \%$ CTO-PCI procedural success rate in our study is higher than the $53 \%$ and $59 \%$ rates in recent studies and remained stable over the 4-year study period $[11,12]$. Our data are from 2012-2015 and therefore reflect recent improvements in equipment and techniques. This procedural success rate is in keeping with the $79.7 \%$ and $74 \%$ rates reported previously [6,13]. However, patient selection may also have contributed to our procedural success rate. Few centers had high CTO-PCI volumes. Interventional cardiologists with limited experience in CTO-PCI may reserve PCI for cases of limited complexity, thus increasing their success rate. During the study period, the CTO-PCI volume increased almost 3-fold. This finding probably reflects growing confidence in CTO-PCI and its benefits for patients $[6,14]$. 
Radiation exposure measured by the DAP and air Kerma decreased over the study period. These data are consistent with Cardio-ARSIF registry results in the overall population of PCI patients in the same geographic area [15]. Overall, CTO-PCI volume did not correlate with the CTO-PCI procedural success rate, even after excluding centers performing less than 25 CTO-PCI procedures per year. The overall CTO-PCI procedural success rate was high in our population. As suggested above, this may reflect selection of relatively simple CTO cases for PCI. Thus, a double approach is generally required to treat complex CTO cases but was rarely used in our population. These data suggest that volume of the center is not a good reflection of the good management of CTOs. Previous studies showed that CTO-PCI volume per interventional cardiologist correlated more closely with the procedural success rate than did the CTO-PCI volume per center $[11,12,16]$.

This study has substantial limitations. First of all, our choice to compare data from an unselected population overestimates the differences between the CTO and non-CTO groups since a number of included patients in the non-CTO group have no significant coronary lesions but only coronary atheroma. However, the aim of the study was not to be limited to population with severe coronary lesions, this subject has been studied extensively in the literature, but to assess the importance of the CTO field in the daily activity of cathlabs in a stable unselected population. Second, the observational design can produce information on associations but cannot obtain evidence of causality. Third, the CARDIO-ARSIF registry is limited to the greater Paris area where the density of physicians is higher than most areas in France. Fourth, angiographic information about CTO (e.g J-CTO score) are not recorded in the registry nor are procedure technique and clinical outcomes. Fifth, numbers of PCIs and of CTO-PCIs per interventional cardiologist were not available. Finally, follow-up is limited to the hospital mortality and long term data is not recorded in the registry.

\section{$\underline{\text { References }}$}


1. Christofferson RD, Lehmann KG, Martin GV, Every N, Caldwell JH, Kapadia SR. Effect of chronic total coronary occlusion on treatment strategy. Am J Cardiol 2005;95:10881091.

2. Fefer P, Knudtson ML, Cheema AN, Galbraith PD, Osherov AB, Yalonetsky S, Gannot S, Samuel M, Weisbrod M, Bierstone D, Sparkes JD, Wright GA, Strauss BH. Current perspectives on coronary chronic total occlusions: the Canadian Multicenter Chronic Total Occlusions Registry. J Am Coll Cardiol 2012;59:991-997.

3. Jeroudi OM, Alomar ME, Michael TT, Sabbagh AE, Patel VG, Mogabgab O, Fuh E, Sherbet D, Lo N, Roesle M, Rangan BV, Abdullah SM, Hastings JL, Grodin J, Banerjee S, Brilakis ES. Prevalence and Management of Coronary Chronic Total Occlusions in a Tertiary Veterans Affairs Hospital. Catheter Cardiovasc Interv 2014;84:637-643.

4. Råmunddal T, Hoebers LP, Henriques JPS, Dworeck C, Angerås O, Odenstedt J, Ioanes D, Olivecrona G, Harnek J, Jensen U, Aasa M, Albertsson P, Wedel H, Omerovic E. Prognostic Impact of Chronic Total Occlusions: A Report From SCAAR (Swedish Coronary Angiography and Angioplasty Registry). JACC Cardiovasc Interv 2016;9:1535-1544.

5. Råmunddal T, Hoebers LP, Hoebers L, Henriques JPS, Dworeck C, Angerås O, Odenstedt J, Ioanes D, Olivecrona G, Harnek J, Jensen U, Aasa M, Jussila R, James S, Lagerqvist B, Matejka G, Albertsson P, Omerovic E. Chronic total occlusions in Sweden-a report from the Swedish Coronary Angiography and Angioplasty Registry (SCAAR). PloS One 2014;9:e103850.

6. Tomasello SD, Boukhris M, Giubilato S, Marzà F, Garbo R, Contegiacomo G, Marzocchi A, Niccoli G, Gagnor A, Varbella F, Desideri A, Rubartelli P, Cioppa A, Baralis G, Galassi AR. Management strategies in patients affected by chronic total occlusions: 
results from the Italian Registry of Chronic Total Occlusions. Eur Heart J 2015;36:31893198.

7. Werner GS, Gitt AK, Zeymer U, Juenger C, Towae F, Wienbergen H, Senges J. Chronic total coronary occlusions in patients with stable angina pectoris: impact on therapy and outcome in present day clinical practice. Clin Res Cardiol 2009;98:435-441.

8. Claessen BE, Dangas GD, Weisz G, Witzenbichler B, Guagliumi G, Möckel M, Brener SJ, Xu K, Henriques JPS, Mehran R, Stone GW. Prognostic impact of a chronic total occlusion in a non-infarct-related artery in patients with ST-segment elevation myocardial infarction: 3-year results from the HORIZONS-AMI trial. Eur Heart J 2012;33:768-775.

9. Claessen BEPM, van der Schaaf RJ, Verouden NJ, Stegenga NK, Engstrom AE, Sjauw KD, Kikkert WJ, Vis MM, Baan J, Koch KT, de Winter RJ, Tijssen JGP, Piek JJ, Henriques JPS. Evaluation of the effect of a concurrent chronic total occlusion on longterm mortality and left ventricular function in patients after primary percutaneous coronary intervention. JACC Cardiovasc Interv 2009;2:1128-1134.

10. Puymirat E, Simon T, Cayla G, Cottin Y, Elbaz M, Coste P, Lemesle G, Motreff P, Popovic B, Khalife K, Labèque J-N, Perret T, Le Ray C, Orion L, Jouve B, Blanchard D, Peycher P, Silvain J, Steg PG, Goldstein P, Guéret P, Belle L, Aissaoui N, Ferrières J, Schiele F, Danchin N, USIK, USIC 2000, and FAST-MI investigators. Acute Myocardial Infarction: Changes in Patient Characteristics, Management, and 6-Month Outcomes Over a Period of 20 Years in the FAST-MI Program (French Registry of Acute ST-Elevation or Non-ST-Elevation Myocardial Infarction) 1995 to 2015. Circulation 2017;136:19081919.

11. Hannan EL, Zhong Y, Jacobs AK, Stamato NJ, Berger PB, Walford G, Sharma S, Venditti FJ, King SB. Patients With Chronic Total Occlusions Undergoing Percutaneous 
Coronary Interventions: Characteristics, Success, and Outcomes. Circ Cardiovasc Interv 2016;9:e003586.

12. Brilakis ES, Banerjee S, Karmpaliotis D, Lombardi WL, Tsai TT, Shunk KA, Kennedy KF, Spertus JA, Holmes DR, Grantham JA. Procedural outcomes of chronic total occlusion percutaneous coronary intervention: a report from the NCDR (National Cardiovascular Data Registry). JACC Cardiovasc Interv 2015;8:245-253.

13. Tsai TT, Stanislawski MA, Shunk KA, Armstrong EJ, Grunwald GK, Schob AH, Valle JA, Alfonso CE, Nallamothu BK, Ho PM, Rumsfeld JS, Brilakis ES. Contemporary Incidence, Management, and Long-Term Outcomes of Percutaneous Coronary Interventions for Chronic Coronary Artery Total Occlusions: Insights From the VA CART Program. JACC Cardiovasc Interv 2017;10:866-875.

14. Galassi AR, Brilakis ES, Boukhris M, Tomasello SD, Sianos G, Karmpaliotis D, Di Mario C, Strauss BH, Rinfret S, Yamane M, Katoh O, Werner GS, Reifart N. Appropriateness of percutaneous revascularization of coronary chronic total occlusions: an overview. Eur Heart J 2016;37:2692-2700.

15. Georges J-L, Karam N, Tafflet M, Livarek B, Bataille S, Loyeau A, Mapouata M, Benamer H, Caussin C, Garot P, Varenne O, Barbou F, Teiger E, Funck F, Karrillon G, Lambert Y, Spaulding C, Jouven X, CARDIO-ARSIF Registry Investigators*. TimeCourse Reduction in Patient Exposure to Radiation From Coronary Interventional Procedures: The Greater Paris Area Percutaneous Coronary Intervention Registry. Circ Cardiovasc Interv 2017;10:e05268.

16. Thompson CA, Jayne JE, Robb JF, Friedman BJ, Kaplan AV, Hettleman BD, Niles NW, Lombardi WL. Retrograde techniques and the impact of operator volume on percutaneous intervention for coronary chronic total occlusions an early U.S. experience. JACC Cardiovasc Interv 2009;2:834-842. 
Disclosure statement/ Conflict of interest: None of the authors have conflicts of interest to declare 


\section{$\underline{\text { Figure titles and legends }}$}

Figure 1. Patient flowchart

CTO: chronic total occlusion; PCI: percutaneous coronary intervention; STEMI: ST-segment elevation myocardial infarction; NSTEMI: non-ST-segment elevation myocardial infarction Figure 2. Flowchart of patients with CTO-PCI

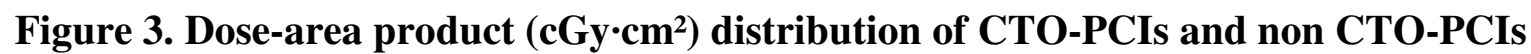

Figure 4. Volume and success rates of CTO-PCI in the centers contributing to the Cardio-ARSIF registry over the study period

Figure 5. Correlation between volume and success rate of PCIs in patients with CTO $(\mathbf{P}=\mathbf{0 . 1 5})$ 
Coronary procedures in CARDIO-ARSIF (2012-2015)

$$
N=258526
$$

Emergent procedures (STEMI, NSTEMI, cardiac arrest): 70431

Prior CABG: 8107

Planned PCl: 26474

Missing data: 10220

Number of coronary angiograms included: $N=143294$

Number of patients included: $N=\underline{128739}$

Coronary angiogram without СТО: $N=131460$

Patients without $\mathrm{CTO}: \mathrm{N}=\underline{118271}$
Coronary angiogram with CTO $\mathrm{N}=11834$

Patients with CTO: $N=\underline{10468}$ 
Non emergent PCI in CARDIO-ARSIF (2012-2015)

$$
N=61469
$$

$\mathrm{PCI}$ not linked to a previous diagnostic coronary angiogram:

$$
N=8976
$$

$\mathrm{PCl}$ more than 1 year after diagnostic CA:

$$
\mathrm{N}=56
$$

Missing data:

$\mathrm{N}=2514$

Number $\mathrm{PCl}$ included: $\mathrm{N}=49923$

Number of patients included: $N=43768$

\section{CTO PCI}

$N=2829(5.7 \%)$

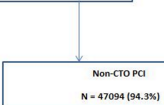




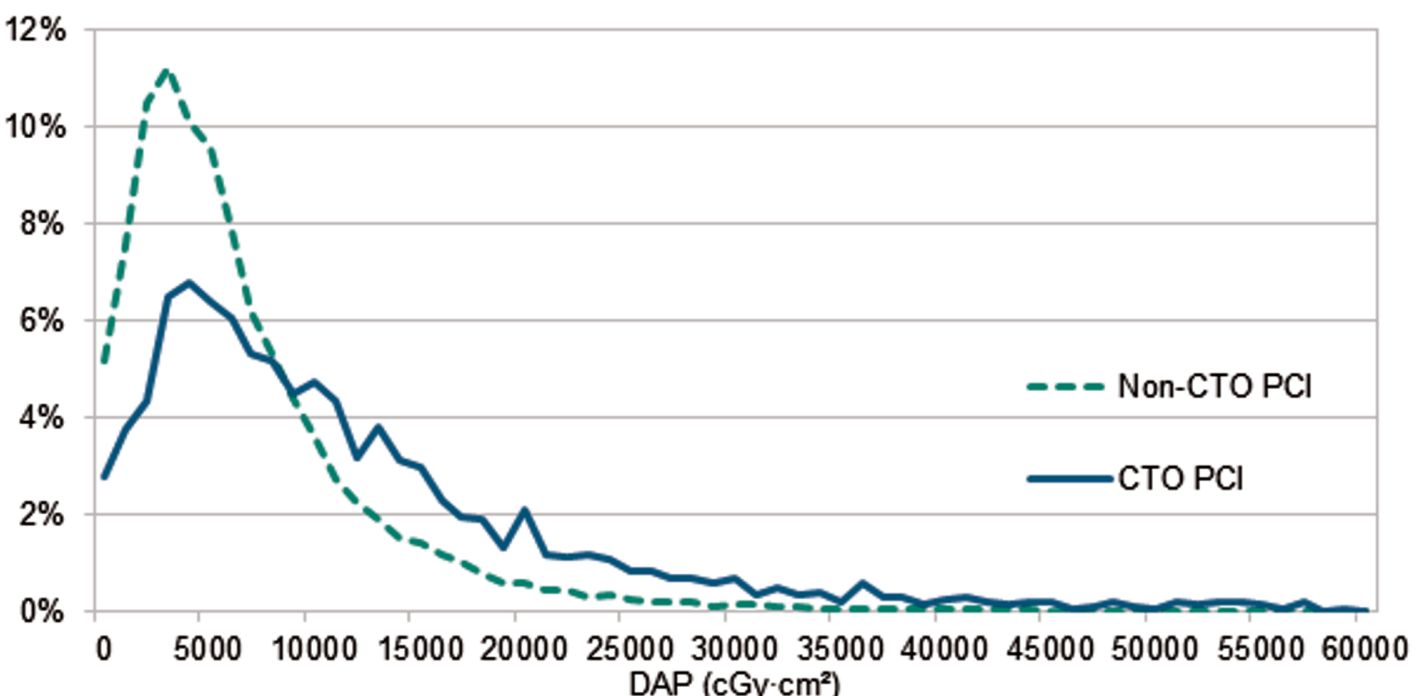




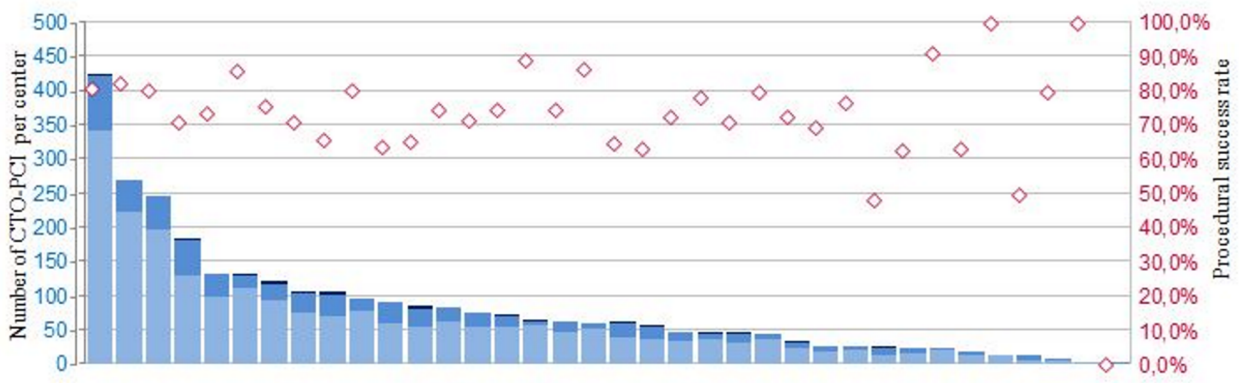

-Intermediate $=$ Failure $=$ Success $\diamond$ Success rate 


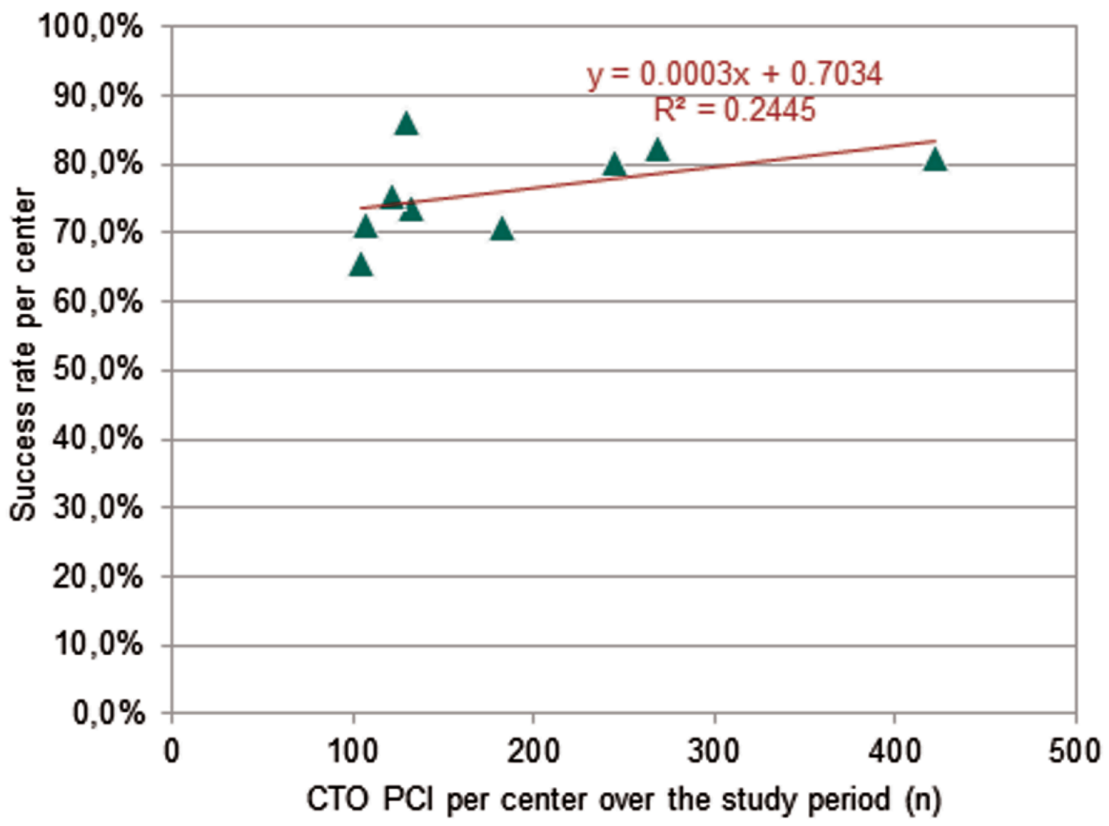


Table 1. Baseline characteristics of patients with coronary chronic total occlusion

\begin{tabular}{|c|c|c|c|c|}
\hline \multirow{3}{*}{ Variable } & \multicolumn{2}{|c|}{ Chronic total occlusion } & \multirow{3}{*}{$\begin{array}{l}\text { Missing data } \\
\text { n }\end{array}$} & \multirow[t]{3}{*}{$P$ value } \\
\hline & & & & \\
\hline & $n=10468$ & $n=118271$ & & \\
\hline Age (years) & $67.4 \pm 11.4$ & $66.7 \pm 12.3$ & $212(0 \%)$ & 0.0008 \\
\hline Men & $8757(84 \%)$ & $81220(69 \%)$ & $307(0 \%)$ & $<0.0001$ \\
\hline $\begin{array}{l}\text { Family history of coronary } \\
\text { artery disease }\end{array}$ & $1458(15 \%)$ & $14736(13 \%)$ & $8600(7 \%)$ & 0.0004 \\
\hline Hypertension & $6516(63 \%)$ & $63508(56 \%)$ & $4130(3 \%)$ & $<0.0001$ \\
\hline Dyslipidemia & $6310(61 \%)$ & $55110(49 \%)$ & $4917(4 \%)$ & $<0.0001$ \\
\hline Overweight* & $3683(67 \%)$ & $27550(64 \%)$ & $5389(10 \%)$ & $<0.0001$ \\
\hline Smoker (ever) & $5363(61 \%)$ & $47223(49 \%)$ & $24380(19 \%)$ & $<0.0001$ \\
\hline Diabetes mellitus & $3636(35 \%)$ & $29712(26 \%)$ & $3562(3 \%)$ & $<0.0001$ \\
\hline $\begin{array}{l}\text { Prior percutaneous coronary } \\
\text { intervention }\end{array}$ & $3479(34 \%)$ & $22725(20 \%)$ & $4770(4 \%)$ & $<0.0001$ \\
\hline Prior myocardial infarction & $1551(15 \%)$ & $6499(6 \%)$ & $3129(2 \%)$ & $<0.0001$ \\
\hline Prior stroke & $460(5 \%)$ & $3335(3 \%)$ & $7700(6 \%)$ & $<0.0001$ \\
\hline Chronic kidney disease & $676(7 \%)$ & $5778(5 \%)$ & $7797(6 \%)$ & $<0.0001$ \\
\hline Peripheral vascular disease & $1421(14 \%)$ & $8714(8 \%)$ & $7525(6 \%)$ & $<0.0001$ \\
\hline $\begin{array}{l}\text { Left ventricle ejection fraction } \\
<\mathbf{5 0} \%\end{array}$ & $3753(38 \%)$ & $49254(45 \%)$ & $9418(7 \%)$ & $<0.0001$ \\
\hline $\begin{array}{l}\text { 1-vessel coronary artery } \\
\text { disease }\end{array}$ & $2700(26 \%)$ & $29245(25 \%)$ & $2023(2 \%)$ & 0.1401 \\
\hline $\begin{array}{l}\text { 2-vessel coronary artery } \\
\text { disease }\end{array}$ & $3678(35 \%)$ & $17352(15 \%)$ & $2023(2 \%)$ & $<0.0001$ \\
\hline $\begin{array}{l}\text { 3-vessel coronary artery } \\
\text { disease }\end{array}$ & $4051(39 \%)$ & $10037(9 \%)$ & $2023(2 \%)$ & $<0.0001$ \\
\hline
\end{tabular}


Values are mean $\pm \mathrm{SD}$ or $\mathrm{n}(\%)$.

Hypertension $=$ systolic blood pressure $>140 \mathrm{~mm} \mathrm{Hg}$, diastolic blood pressure $>90 \mathrm{mmHg}$, or the use of antihypertensive medications; Dyslipidemia = low-density lipoprotein cholesterol $\geq 140 \mathrm{mg} / \mathrm{dl}$, high-density lipoprotein cholesterol $\leq 40 \mathrm{mg} / \mathrm{dl}$, triglyceride $\geq 150 \mathrm{mg} / \mathrm{dl}$, or current treatment with statins and/or lipid-lowering agents; Overweight = body mass index > $25 \mathrm{~kg} / \mathrm{m}^{2}$

* Data available since 2014 
Table2. Therapeutic strategies according to the presence or absence of coronary chronic total occlusion at diagnostic coronary angiography

\begin{tabular}{llll}
\hline Variable & \multicolumn{2}{c}{ Chronic total occlusion } & P value \\
& Yes & 131460 & \\
\hline Coronary angiogram (n) & 11834 & 6407 & \\
Missing data & 556 & $50712(41 \%)$ & $<0.0001$ \\
Medical treatment & $2381(21 \%)$ & $6058(5 \%)$ & $<0.0001$ \\
Coronary bypass & $1101(10 \%)$ & $29367(23 \%)$ & $<0.0001$ \\
$\begin{array}{l}\text { Ad hoc percutaneous } \\
\text { coronary intervention }\end{array}$ & $3530 *(31 \%)$ & & $<0.0001$ \\
Planned percutaneous & $2012 *(18 \%)$ & $12458(10 \%)$ & $<0.0001$ \\
coronary intervention & & $9073(7 \%)$ & $<0.0001$ \\
Heart team referral & $2009(18 \%)$ & $10359(8 \%)$ & $<0.0001$ \\
No treatment & $35(0 \%)$ & $5008(4 \%)$ & $<0.0001$ \\
Valve surgery & $128(1 \%)$ & $2018(2 \%)$ & \\
Other & $82(1 \%)$ & 125053 & \\
Total & 11278 & & \\
\hline & & & \\
\hline
\end{tabular}

Values are $n(\%)$.

* PCI could involve CTO or non-CTO lesion 
Table3. Comparison of percutaneous coronary intervention indications and vascular access between patients treated for coronary chronic total occlusion or not

\begin{tabular}{|c|c|c|c|c|}
\hline Indication & $\begin{array}{l}\text { CTO-PCI } \\
(\mathbf{N}=2829)\end{array}$ & $\begin{array}{l}\text { Non-CTO-PCI } \\
(\mathrm{N}=47094)\end{array}$ & Missing data & $P$ value \\
\hline Angina pectoris & $1433(52 \%)$ & $22639(50 \%)$ & $3 \%$ & 0.0936 \\
\hline Silent myocardial ischemia & $918(36 \%)$ & $11811(31 \%)$ & $18 \%$ & $<0.0001$ \\
\hline $\begin{array}{l}\text { Documented myocardial } \\
\text { ischemia }\end{array}$ & $2440(87 \%)$ & $37424(81 \%)$ & $2 \%$ & $<0.0001$ \\
\hline \multicolumn{5}{|l|}{ Vascular access } \\
\hline Radial & $1788(64 \%)$ & $40230(87 \%)$ & $1 \%$ & $<0.0001$ \\
\hline Femoral & $250(9 \%)$ & $4374(9 \%)$ & $1 \%$ & 0.4406 \\
\hline Multiple & $733(26 \%)$ & $1682(4 \%)$ & $1 \%$ & $<0.0001$ \\
\hline
\end{tabular}

Values are $\mathrm{n}(\%)$.

CTO, chronic total occlusion; PCI, percutaneous coronary intervention; 
Table4. Procedural characteristics of percutaneous coronary interventions performed to treat coronary chronic total occlusion or not

\begin{tabular}{|c|c|c|c|}
\hline Procedural characteristics & $\begin{array}{l}\text { CTO-PCI } \\
\text { N }=2829(5.7 \%)\end{array}$ & $\begin{array}{l}\text { Non CTO-PCI } \\
\text { N = } 47094(94.3 \%)\end{array}$ & $P$ value \\
\hline $\begin{array}{l}\text { Fluoroscopy time } \\
\text { (minutes) }\end{array}$ & $20: 49(12: 46-34: 37)$ & $10: 19(6: 33-16: 30)$ & $<0.0001$ \\
\hline $\begin{array}{l}\text { Dose Area Product, } c \cdot G y \\
\mathrm{~cm}^{2}, 75^{\text {th }} \text { percentile }\end{array}$ & $9011(4640-15769)$ & $5122(2754-8854)$ & $<0.0001$ \\
\hline $\begin{array}{l}\text { Number of stents per } \\
\text { percutaneous coronary } \\
\text { intervention }\end{array}$ & $1.93 \pm 0.92$ & $1.50 \pm 0.79$ & $<0.0001$ \\
\hline $\begin{array}{l}\text { Stent length per } \\
\text { percutaneous coronary } \\
\text { intervention }(\mathbf{m m})\end{array}$ & $46.94 \pm 26.42$ & $28.11 \pm 17.64$ & $<0.0001$ \\
\hline Stent diameter (mm) & $2.76 \pm 0.40$ & $2.92 \pm 0.47$ & $<0.0001$ \\
\hline Procedural success & $75.7 \%$ & $97.1 \%$ & \\
\hline
\end{tabular}

Values are median $(\mathrm{Q} 1-\mathrm{Q} 3)$ or mean \pm SD unless stated otherwise. 
Table5. Changes in procedural parameters of coronary chronic total occlusion percutaneous coronary interventions over the study period

\begin{tabular}{|c|c|c|c|c|c|c|c|c|}
\hline & 2012 & 2013 & 2014 & 2015 & $\begin{array}{l}2012- \\
2013 \\
P \\
\text { value* }\end{array}$ & $\begin{array}{l}2013- \\
2014 \\
P \\
\text { value* }\end{array}$ & $\begin{array}{l}2014- \\
2015 \\
P \\
\text { value* }\end{array}$ & $\begin{array}{l}\text { TOTAL } \\
P \text { value } \dagger\end{array}$ \\
\hline $\begin{array}{l}\text { Fluoroscopy time }(\mathrm{min}) \\
\text { median }\end{array}$ & $25: 04$ & $21: 21$ & $19: 10$ & $20: 16$ & 0.0009 & 0.0155 & 0.2451 & $<0.0001$ \\
\hline $\begin{array}{l}\text { Dose area product, } \mathrm{c} \cdot \mathrm{Gy} \\
\mathrm{cm}^{2}(75 \text { th percentile })\end{array}$ & 24152 & 16541 & 15104 & 14000 & $<0.0001$ & 0.011 & 0.0037 & $<0.0001$ \\
\hline $\begin{array}{l}\text { Bare metal stent per } \\
\text { percutaneous coronary } \\
\text { intervention (mean) }\end{array}$ & 0.17 & 0.19 & 0.16 & 0.08 & 0.5274 & 0.4277 & 0.0006 & 0.0005 \\
\hline $\begin{array}{l}\text { Drug eluting stent per } \\
\text { percutaneous coronary } \\
\text { intervention (mean) }\end{array}$ & 1.89 & 1.77 & 1.72 & 1.81 & 0.1128 & 0.5665 & 0.1645 & 0.1576 \\
\hline $\begin{array}{l}\text { Stents per percutaneous } \\
\text { coronary intervention } \\
\text { (mean) }\end{array}$ & 2.06 & 1.96 & 1.88 & 1.90 & 0.2735 & 0.1362 & 0.8531 & 0.0696 \\
\hline Stent length $(\mathrm{mm})$ & 52.28 & 48.1 & 44.74 & 46.31 & 0.0592 & 0.1407 & 0.3575 & 0.0157 \\
\hline Stent diameter $(\mathrm{mm})$ & 2.75 & 2.73 & 2.78 & 2.78 & 0.4774 & 0.0618 & 0.7107 & 0.2803 \\
\hline
\end{tabular}

Values are median $(\mathrm{Q} 1-\mathrm{Q} 3)$ or mean \pm SD unless stated otherwise

* Mann-Whitney U test was used to compare distribution between two different years (2012-

2013, 2013-2014, 2014-2015).

$\dagger$ Kruskal-Wallis test was used to compare distribution of all years ( $\mathrm{p}$ Total) 